\title{
Jebolnya Tanggul Situ Gintung (27 Maret 2009) Bukan Karena Faktor Curah Hujan Ekstrim
}

\author{
Budi Harsoyo ${ }^{1}$
}

\begin{abstract}
Spatial and hidrology analysis has been done to find out the main factor of causing the burst of Situ Gintung dam incident on March 27, 2009. Spatial analysis was done to get some parameters that needs as input for hidology analysis. The analysis results indicating that rain fall actually was be one of cause factors that incident, but not as the main factor. The condition of dike which already broken as the consequence of its life time and also the condition of spill way which has not function as like as innitialy built by Nederland Goverment, is more as principal factor of causing the burst of Situ Gintung dam incident.
\end{abstract}

\section{Intisari}

Analisis spasial dan hidrologi telah dilakukan untuk mengetahui faktor utama yang menyebabkan insiden jebolnya Situ Gintung pada 27 Maret 2009. Analisis spasial dilakukan untuk mendapatkan beberapa parameter yang perlu sebagai masukan untuk analisis hidologi. Hasil analisis menunjukkan bahwa curah hujan sebenarnya menjadi salah satu faktor yang menyebabkan insiden, tetapi tidak sebagai faktor utama. Kondisi tanggul yang sudah rusak sebagai akibat dari waktu hidup dan juga kondisi saluran pembuangan yang belum berfungsi sebagai seperti sebagai awalnya pada saat dibangun oleh Pemerintah Belanda, lebih sebagai faktor utama yang menyebabkan ledakan insiden bendungan Situ Gintung

Kata kunci : spatial analysis, hydrologi analysis, rainfall, Situ Gintung dam

\section{PENDAHULUAN}

Musibah jebolnya tanggul Situ Gintung di daerah Cireundeu, Tangerang Selatan, Banten pada hari Jumat dini hari tanggal 27 Maret 2009 menambah daftar bencana alam yang terjadi di Indonesia dalam beberapa tahun terakhir ini. Lebih dari seratus korban jiwa meninggal dan ratusan korban lainnya mengalami luka - luka dalam musibah ini. Selain itu tercatat sebanyak 260 keluarga kehilangan tempat tinggal akibat air bah bagaikan tsunami yang menghantam daerah permukiman di sekitarnya, yang secara topografi berada di bawah elevasi titik lokasi tanggul yang jebol tersebut. Situ yang dibangun oleh pemerintah kolonial Belanda pada tahun 1932-1933 ini semula didesain untuk keperluan irigasi bagi areal pertanian di sekitarnya, namun kini areal tersebut sudah berubah fungsi menjadi lahan permukiman yang cukup padat. Penduduk

\footnotetext{
${ }^{1}$ Peneliti Pertama UPT Hujan Buatan BPP Teknologi, Jalan MH. Thamrin no. 8, Gd.I Lt.19, Jakarta Pusat

E-mail : buhar04@yahoo.com
}

yang tinggal pada lahan permukiman yang semula adalah lahan pertanian inilah yang menjadi korban dalam bencana tersebut (Gambar 1b, area yang diarsir). Sebagian pihak menganggap bahwa musibah jebolnya tanggul situ yang sudah berumur 76 tahun ini disebabkan karena faktor cuaca ekstrim yaitu tingginya intensitas hujan yang terjadi pada malam harinya, sementara pihak lain menilai bahwa musibah ini terjadi akibat faktor usia bangunan tanggul yang memang sudah terlampau tua dan mengalami kerusakan. Tanpa bermaksud untuk menyudutkan pihak-pihak tertentu, tulisan ini ingin membuktikan bahwa musibah jebolnya tanggul Situ Gintung bukan disebabkan oleh curah hujan ekstrim sebagai faktor utamanya, tetapi lebih kepada faktor usia tanggul yang sudah melampaui umur ekonomisnya, dan akhirnya mengalami kerusakan karena tidak lagi sanggup menahan beban air di dalam situ. Penulis menganalisis faktor penyebab terjadinya musibah tersebut melalui pendekatan secara spasial dan hidrologis. Analisis spasial dilakukan untuk mendapatkan beberapa parameter yang diperlukan sebagai masukan dalam 


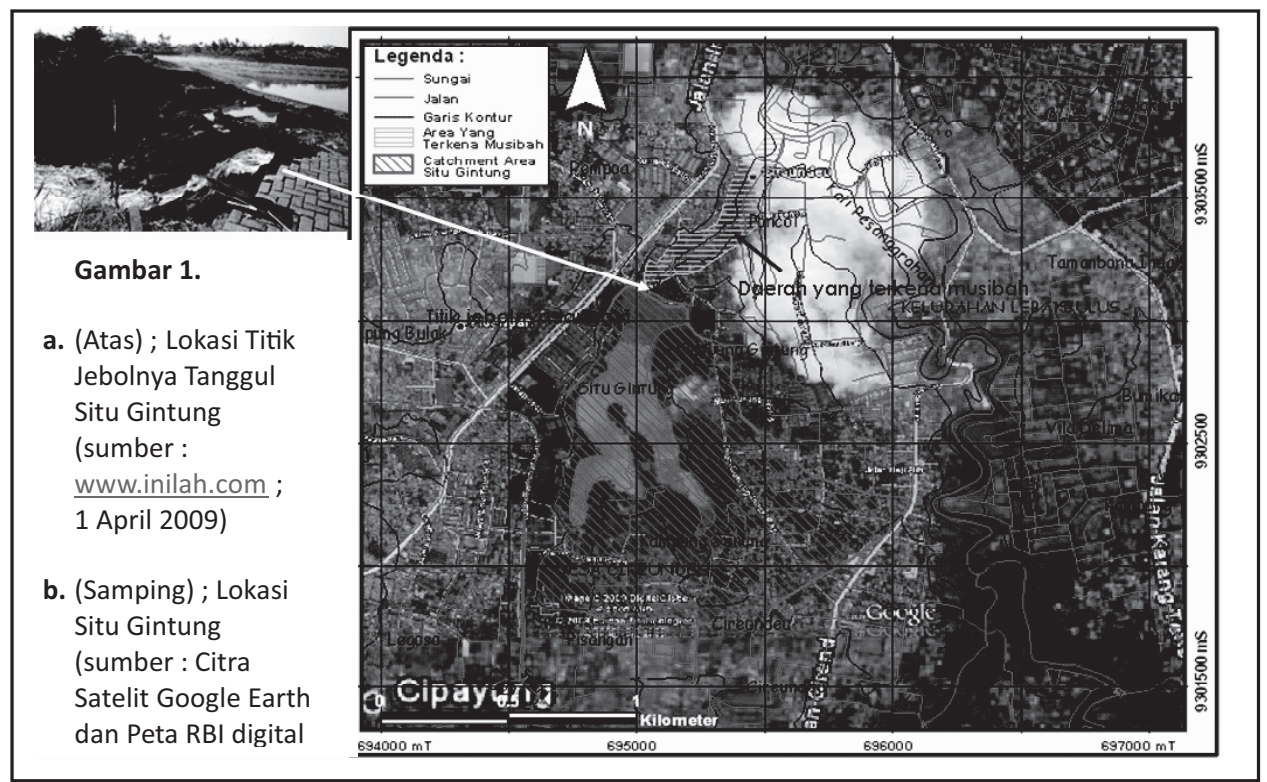

Gambar 1. Lokasi Tanggul Situ Gintung

melakukan analisis hidrologi. Sebagian data yang digunakan dalam melakukan analisis merupakan data sekunder yang diambil dari beberapa artikel surat kabar ataupun di internet sebagai referensi.

\section{Analisis Spasial}

\subsection{Kondisi Topografi dan Catchment Area Situ Gintung}

Berdasarkan hasil analisis spasial dengan menggunakan data citra satelit dari Google Earth
2), terlihat bahwa kondisi topografi di sekitar Situ Gintung relatif datar, sehingga sebenarnya agak sulit untuk membatasi daerah tangkapan air (catchment area) nya. Dengan tidak adanya aliran sungai yang masuk sebagai inlet bagi reservoir Situ Gintung, batas catchment area didelineasi dengan mengacu pada data Digital Elevation Model (DEM) yang dibangun berdasarkan layer kontur dari Peta RBI digital skala 1:25.000. Kali Pesanggrahan mengalir di sebelah timur Situ Gintung, dan aliran sungainya menyatu dengan aliran dari outlet Situ Gintung di titik lokasi permukiman yang tergenang

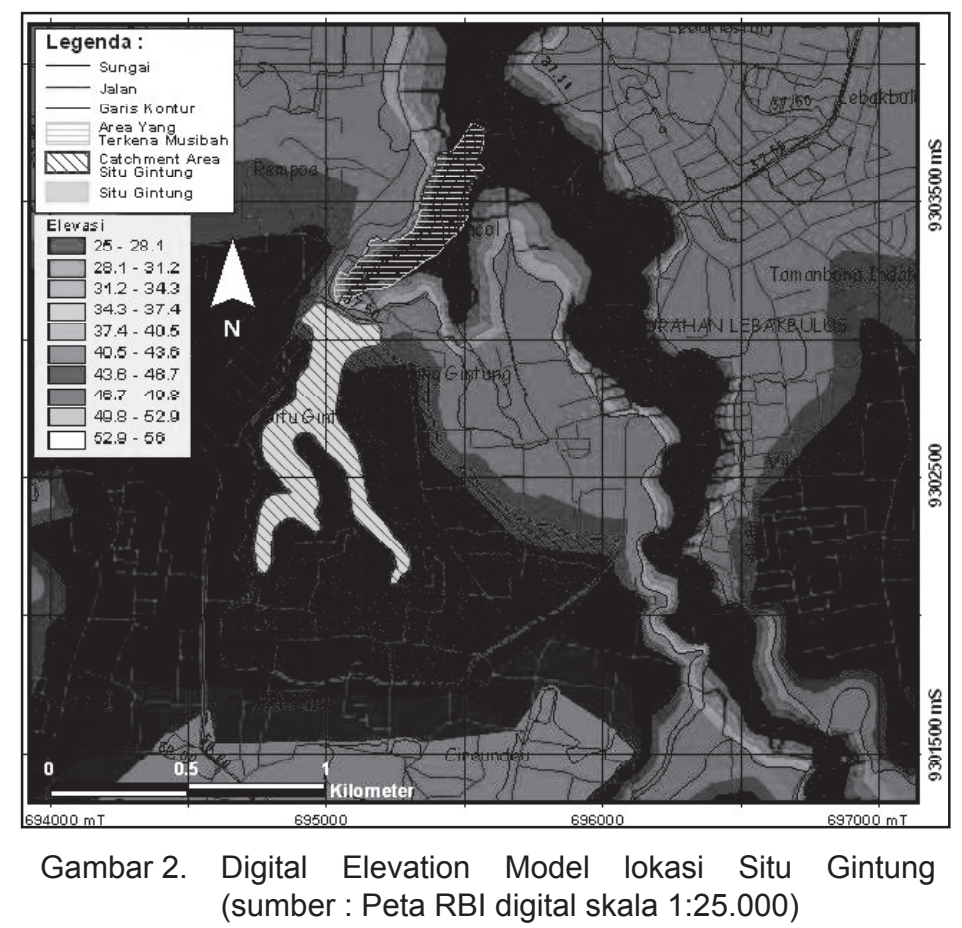

yang dipadukan dengan Peta Rupa Bumi Indonesia (RBI) dari Bakosurtanal skala 1:25.000 (Gambar akibat luapan air dari tanggul yang jebol di Desa Poncol, seperti terlihat pada Gambar 2. 


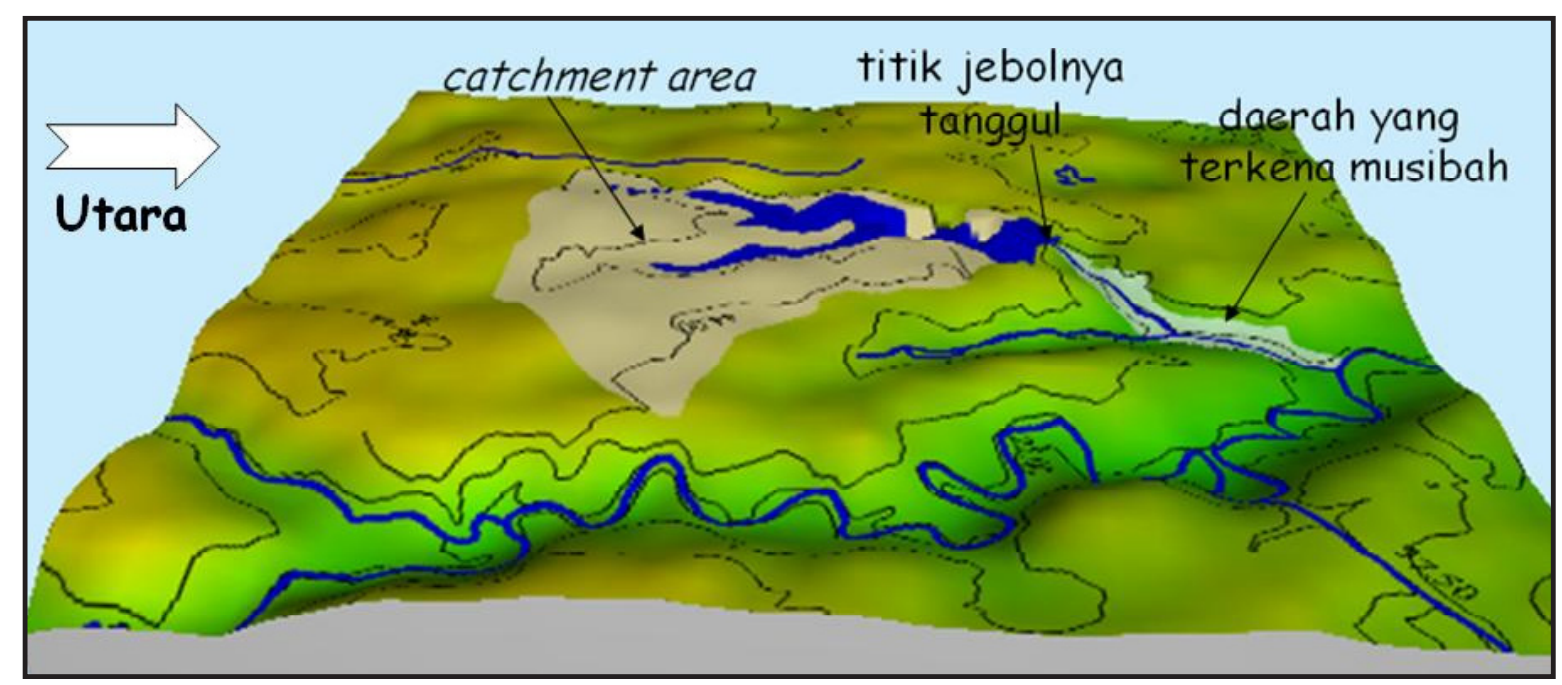

Gambar 3. Kenampakan 3 dimensi catchment area Situ Gintung

Secara umum berdasarkan data Digital Elevasi Mode/ pada Gambar 2, topografi di sebelah selatan Situ Gintung lebih tinggi dibandingkan dengan daerah sekitarnya, dengan elevasi sekitar 49,8-52,9 m. Semakin ke utara elevasinya semakin rendah. Wilayah sekitar tanggul yang jebol mempunyai kisaran elevasi sekitar 40,5-43,6 $\mathrm{m}$, sedangkan wilayah terkena dampak umumnya merupakan wilayah yang lebih rendah dengan elevasi sekitar 25-28,1 m. Perbedaan tinggi antara wilayah tanggul dengan wilayah terkena dampak lebih dari $20 \mathrm{~m}$, sehingga dapat dibayangkan bagaimana dahsyatnya terjangan air yang menyapu habis daerah permukiman di bawah tanggul pada saat tanggul jebol. Kenampakan 3 dimensi dari catchment area Situ Gintung digambarkan dalam Gambar 3.

Menurut Kepala Bidang Mitigasi Bencana BPPT, SutopoPurwo Nugroho (dalamartikeldiharian Kompas, 1 April 2009) Situ Gintung mendapatkan suplai air dari cathment area dan mata air asli di lokasi tersebut. Berdasarkan hasil analisis Sistem Informasi Geografis (SIG), luas catchment area Situ Gintung adalah 112,542 ha dan luas tubuh air Situ Gintung sendiri adalah 21,407 ha. Kepala Balai Besar Wilayah Sungai Ciliwung Cisadane, Pitoyo Subandrio (dalam artikel di harian Kompas, 28 Maret 2009) menjelaskan bahwa saat pertama kali dibangun oleh Belanda, Situ Gintung memiliki luas sekitar 31 ha dengan kedalaman sekitar $10 \mathrm{~m}$. Namun akibat pendangkalan, luasan situ semakin berkurang hingga hanya tersisa sekitar 21,4 ha dengan kedalaman air situ diperkirakan tinggal sekitar $4 \mathrm{~m}$. Dengan demikian maka volume air yang ada dalam waduk adalah sekitar $856.000 \mathrm{~m}^{3}$.

\subsection{Kondisi Penggunaan Lahan dan Area Yang Terkena Musibah}

Tabel 1 menyajikan hasil analisis penggunaan lahan berdasarkan data Peta RBI digital skala 1:25.000 dari Bakosurtanal. Sebaran spasial penggunaan lahan dalam catchment area Situ Gintung dapat dilihat dalam Gambar 4. Dari Gambar 4 juga terlihat bahwa pada wilayah yang terkena musibah yaitu Desa Poncol dan Desa Gintung, area permukiman adalah yang paling luas ( $5,3 \mathrm{ha}$ ), sementara sisanya adalah tegalan/ladang (3,6 ha) dan kebun (2,0 ha).

Tabel 1. Penggunaan Lahan di catchment area Situ Gintung

\begin{tabular}{|l|r|r|}
\hline \multirow{2}{*}{ Penggunaan Lahan } & \multicolumn{2}{|c|}{ Luas } \\
\cline { 2 - 3 } & \multicolumn{1}{|c|}{$\mathrm{Ha}$} & \multicolumn{1}{c|}{ (\%) } \\
\hline Pemukiman & 51,4 & 45,6 \\
\hline Tegalan/Ladang & 18,0 & 16,0 \\
\hline Tubuh air & 19,0 & 16,9 \\
\hline Kebun/Perkebunan & 20,0 & 17,8 \\
\hline Rumput/Tanah kosong & 3,9 & 3,4 \\
\hline Gedung & 0,2 & 0,2 \\
\hline Total & $\mathbf{1 1 2 , 5}$ & $\mathbf{1 0 0 , 0}$ \\
\hline
\end{tabular}




\section{Analisis Hidrologi}

\subsection{Kondisi Curah Hujan}

Ada banyak versi yang menyebutkan intensitas hujan yang terjadi pada tanggal 26 Maret 2009, atau sehari/semalam sebelum kejadian jebolnya tanggul di pagi harinya. Stasiun Meteorologi Ciputat yang merupakan stasiun terdekat dengan lokasi kejadian mencatat curah hujan pada tanggal 26 Maret 2009 sebesar 113,2 $\mathrm{mm} /$ hari, sementara dari Stasiun Meteorologi Pondok Betung curah hujan normal selama 3 jam disusul dengan curah hujan ekstrem $70 \mathrm{~mm}$ selama 1,5 jam (Kompas, 1 April 2009). Ditambahkan oleh Deputi Bidang Sistem Data dan Informasi Badan Meteorologi dan Geofisika (BMG) Prih Harjadi di dalam situs www.okezone.com (31 Maret 2009), curah hujan terdekat lainnya dari Stasiun Ciputat tercatat di Stasiun Lebak Bulus dengan intensitas hujan sebesar $83 \mathrm{~mm} /$ hari.

Sumber lain menurut Fadli Syamsudin (Kompas, 1 April 2009) yang melakukan analisis cuaca menggunakan citra satelit GMS MTSAT pada tanggal 26 dan 27 Maret 2009 dan radar cuaca program HARIMAU (Hydrometeorological ARray for Intraseasonal Monsoon AUtomonitoring) Badan Pengkajian dan Penerapan Teknologi (BPPT) yang berlokasi di Puspiptek, Serpong, menyebutkan bahwa terjadi dua tahapan fase curah hujan tinggi cenderung ekstrem $80-100 \mathrm{~mm} / \mathrm{jam}$ pada 26 Maret pukul 13.00-14.30 (1,5 jam) dengan luasan 15 km x $15 \mathrm{~km}$ dan pukul 16.00-19.30 (3,5 jam) dengan luasan 25 km x 25 km di wilayah Situ Gintung dan sekitarnya.

Sebagai data pendukung tambahan, digunakan juga data curah hujan untuk beberapa tahun periode ulang di Stasiun Ciputat berdasarkan Laporan Kegiatan Project Cisadane River Basin Development Fisibility Study tahun 1987, yang dibuat oleh Departemen Pekerjaan Umum bekerjasama dengan Lavalin Int. Inc., Nippon Koei Co.Ltd. seperti yang tersaji dalam Tabel 2 berikut

Tabel 2. Berbagai Periode Ulang Curah Hujan di Stasiun Ciputat

\begin{tabular}{|c|c|c|c|c|c|c|}
\hline \multirow{2}{*}{ Tahun } & \multicolumn{5}{|c|}{ Periode Ulang } \\
\cline { 2 - 7 } & $\mathbf{2}$ & $\mathbf{5}$ & $\mathbf{1 0}$ & $\mathbf{2 0}$ & $\mathbf{5 0}$ & $\mathbf{1 0 0}$ \\
\hline $\mathbf{m m} /$ hari & 88 & 120 & 141 & 161 & 187 & 206 \\
\hline
\end{tabular}

Sumber: Departemen Pekerjaan Umum RI, 1987

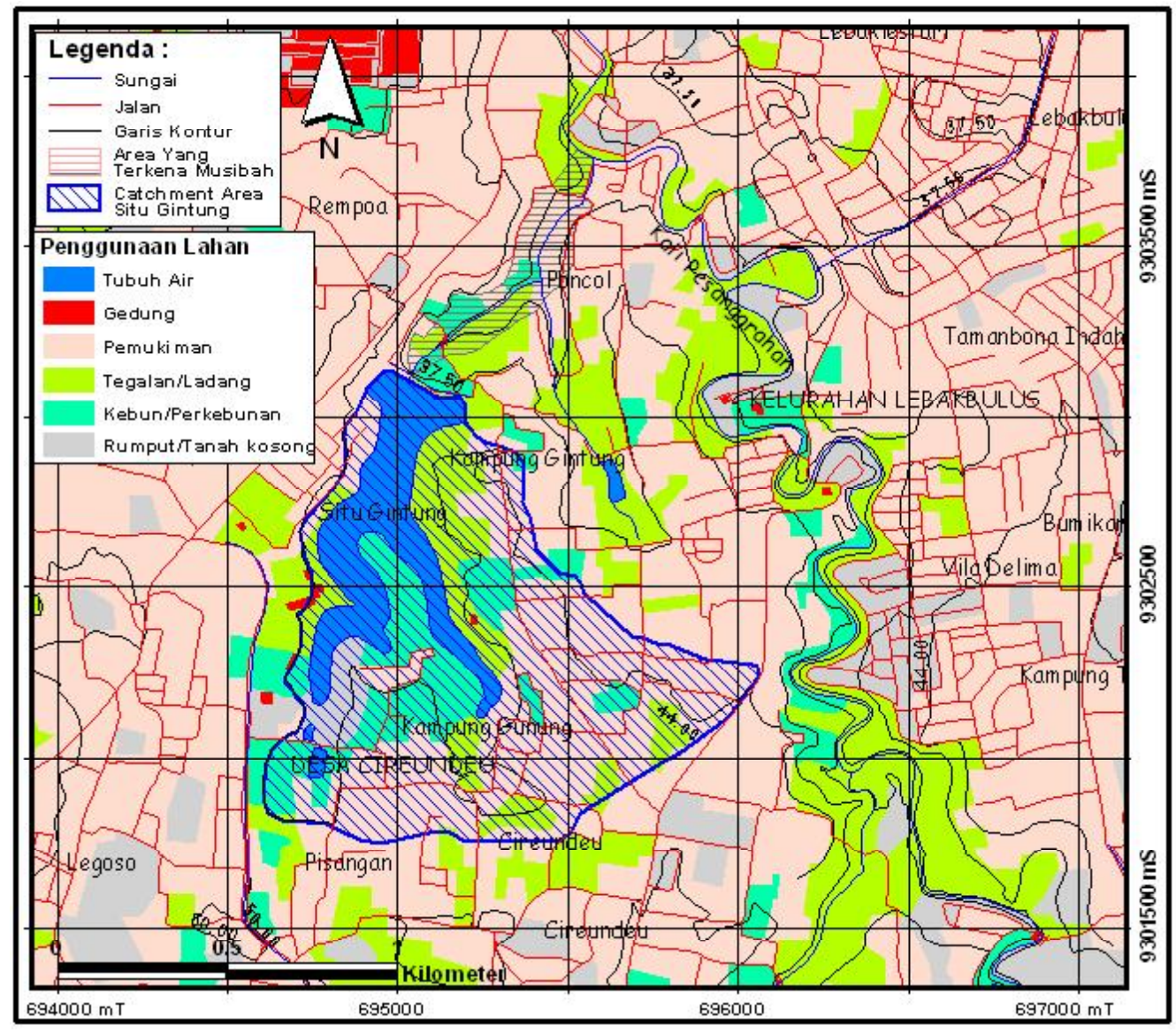

Gambar 4. Peta penggunaan lahan daerah Situ Gintung dan sekitarnya (sumber : Peta RBI digital Bakosurtanal skala 1:25.000) 
Jika mengacu pada data periode ulang untuk Stasiun Ciputat, sebetulnya curah hujan yang terjadi pada tanggal 26 Maret $2009(113,2 \mathrm{~mm} / \mathrm{hari})$ masih tergolong rendah, dan terjadi untuk periode ulang yang pendek (sekitar 5 tahunan). Ini berarti curah hujan yang terjadi pada tanggal 26 Maret 2009 bukan merupakan curah hujan yang ekstrim karena ternyata berdasarkan Tabel 2, nilai curah hujan sebesar 113,2 $\mathrm{mm} /$ hari hanya merupakan nilai dari suatu periode ulang yang pendek.

\subsection{Waktu Konsentrasi (Tc)}

Waktu konsentrasi (disimbolkan Tc) adalah waktu perjalanan yang diperlukan oleh air dari tempat yang paling jauh (hulu DAS) sampai ke titik pengamatan aliran air (outlet). Hal ini terjadi ketika tanah sepanjang kedua titik tersebut telah jenuh dan semua cekungan bumi lainnya telah terisi oleh air hujan. Diasumsikan bahwa bila lama waktu hujan sama dengan Tc berarti seluruh bagian DAS tersebut telah ikut berperan untuk terjadinya aliran air (debit) yang sampai ke titik pengamatan. Salah satu teknik untuk menghitung Tc adalah persamaan matematik yang dikembangkan oleh Kiprich (1940) sebagai berikut :

$$
\mathrm{TC}=0,0195 \mathrm{~L}^{0,77} \mathrm{~S}^{-0,385} \quad \ldots . .(\mathrm{P} .1)
$$

Gambar 5 memperlihatkan profil melintang dari catchment area Situ Gintung yang diambil antara titik outlet (titik jebolnya tanggul) dengan titik pada bagian hulu catchment area. Beda jarak horizontal antara kedua titik tersebut sekitar 1,4 km sedangkan beda jarak vertikalnya sekitar $5,6 \mathrm{~m}$.

Berdasarkan data yang dapat diambil dari profil melintang pada Gambar 5, panjang maksimum aliran $(L)$ dianggap mempunyai nilai $1,4 \mathrm{~km}=1.400$ $\mathrm{m}$; dan beda tinggi antara titik pengamatan dengan lokasi terjauh pada bagian hulu DAS (S) adalah 5,6 $\mathrm{m}$, maka nilai $\mathrm{S}$ adalah $5,6 \mathrm{~m} / 1.400 \mathrm{~m}=0,004$. Berdasarkan nilai $L$ dan $S$ dari hasil perhitungan di atas, maka lamanya waktu konsentrasi berdasarkan Persamaan 1 adalah sebagai berikut :

$$
\begin{aligned}
\text { Tc } & =0,0195 \mathrm{~L}^{0,77} \mathrm{~S}^{-0,385} \\
& =0,0195(1.400)^{0,77}(5,6 / 1.400)^{-0,385} \\
& =0,0195(1.400)^{0,77}(0,004)^{-0,385} \\
& =43,2275 \text { menit } \\
& =0,72 \text { jam }
\end{aligned}
$$

\subsection{Koefisien Aliran (C)}

Perhitungan koefisien aliran dilakukan dengan tabulasi untuk setiap jenis penggunaan lahan, hasilnya tersaji dalam Tabel 3. Faktor luasan tiap jenis penggunaan lahan dijadikan sebagai

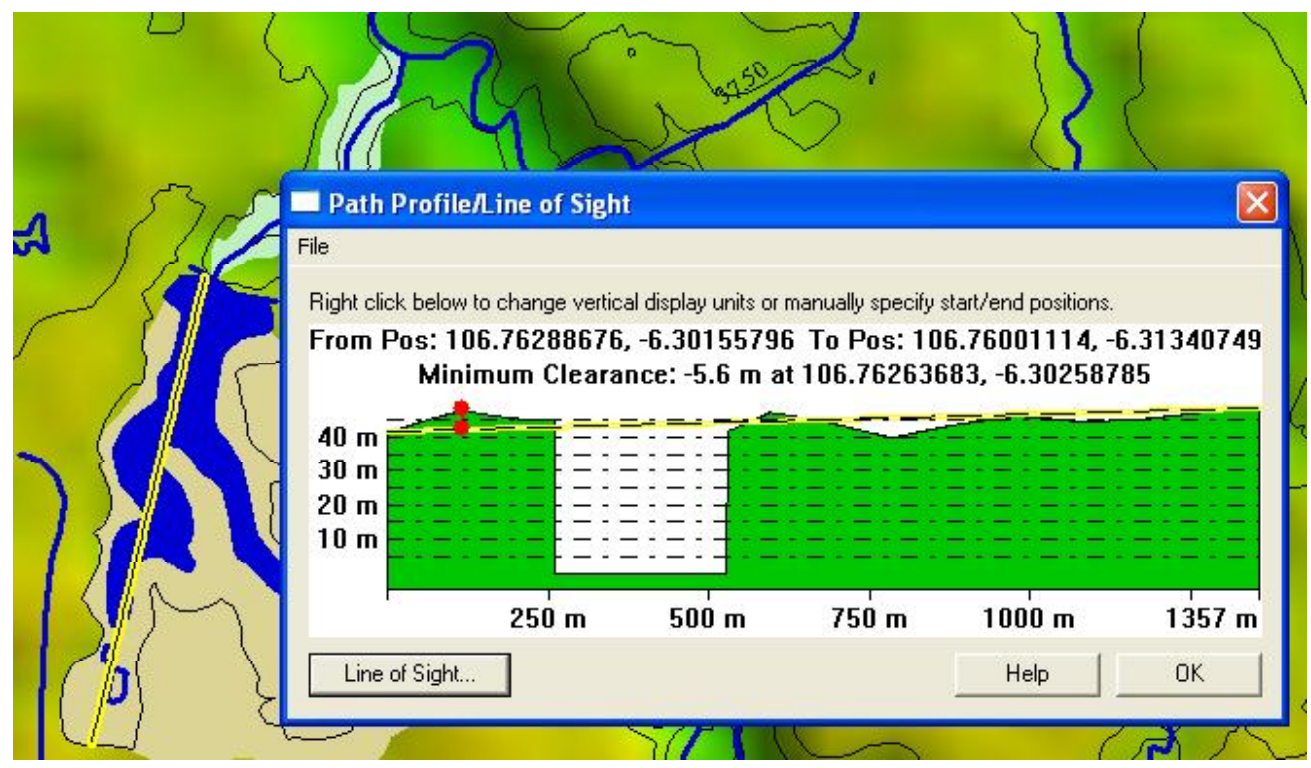

Gambar 5. Profil melintang catchment area Situ Gintung

Dimana :

$\begin{aligned} \mathrm{Tc}= & \text { Waktu konsentrasi (menit) } \\ \mathrm{L}= & \text { Panjang maksimum aliran (meter) } ; \\ \mathrm{S}= & \text { beda ketinggian antara titik } \\ & \text { pengamatan dengan lokasi terjauh } \\ & \text { pada DAS dibagi panjang } \\ & \text { maksimum aliran. } \\ \text { Untuk } & \text { mempermudah perhitungan Tc, }\end{aligned}$ faktor pembobot (weighing factors). Rumus yang digunakan adalah sebagai berikut :

$C=\frac{C 1 . a 1+C 2 . a 2+C 3 . a 3+\ldots . . .+C \text { n.an }}{A}$

Dimana :

C = Koefisien seluruh DAS 
C1= Koefisien Aliran Tabel menurut penggunaan lahan 1 sampai $n$

a = Luas masing-masing penggunaan lahan dari 1 sampai $n$

$\mathrm{A}=$ Luas total penggunaan lahan ada, yang paling mendekati adalah $80-100 \mathrm{~mm} /$ jam (sumber : Fadli Syamsudin, Kompas, 1 April 2009). Namun nilai ini pun dianggap masih belum sama dengan waktu konsentrasinya, sehingga perlu disamakan terlebih dahulu. Dengan asumsi

Tabel 3. Perhitungan Koefisien Aliran (C)

\begin{tabular}{|c|c|c|c|c|}
\hline Penggunaan Lahan & $\begin{array}{c}\text { Luas }(\mathrm{Ha}) \\
-1-\end{array}$ & $\begin{array}{l}\text { (\%) Luas } \\
\quad-2 \text { - }\end{array}$ & $\begin{array}{c}C \\
-3-\end{array}$ & $\begin{array}{l}C \text { tertimbang } \\
-\left(2^{*} 3\right) / 100-\end{array}$ \\
\hline Pemukiman & 51,4 & 45,6 & 0,60 & 0,2736 \\
\hline Tegalan & 18,0 & 16,0 & 0,50 & 0,0800 \\
\hline Badan air & 19,0 & 16,9 & 0,90 & 0,1521 \\
\hline Kebun & 20,0 & 17,8 & 0,40 & 0,0712 \\
\hline Rumput/tanah kosong & 3,9 & 3,4 & 0,50 & 0,0170 \\
\hline Gedung & 0,2 & 0,2 & 0,70 & 0,0014 \\
\hline Total & 112,5 & 100,0 & & 0,5953 \\
\hline
\end{tabular}

Sumber : hasil perhitungan

\subsection{Perhitungan Debit Puncak (Qmaks) Dengan Metode Rasional}

Perhitungan debit puncak (Qmaks) dilakukan dengan menggunakan rumus metode rasional. Adapun rumus untuk metode rasional adalah sebagai berikut :

Dimana :

$$
Q p=0,0028 \text { C.i.A ..... (P.3) }
$$

Qp = Debit Puncak (m3/dt)

$\mathrm{i} \quad=$ Intensitas Hujan $(\mathrm{mm} / \mathrm{jam})$

C $=$ Koefisien Aliran

A $\quad=$ Luas DAS (ha)

Metoda rasional menyatakan bahwa puncak limpasan pada suatu DAS akan diperoleh pada intensitas hujan maksimum (i) yang lamanya sama dengan waktu konsentrasi (TC). Apabila lama hujannya kurang dari waktu konsentrasi, maka intensitasnya kemungkinan lebih besar akan tetapi luas DAS yang memberikan kontribusi terhadap debit akan lebih kecil dari total luas DAS (A). Apabila lama waktu hujan lebih besar dari waktu konsentrasi maka luas areal sama dengan total luas DAS (A) tetapi intensitasnya kurang dari intensitas hujan pada lama hujan sama dengan Tc.

Yang perlu dicermati dari keterangan pada paragraf di atas adalah dalam penggunaan metode rasional disyaratkan bahwa besarnya harus sama dengan Tc. Berdasarkan beberapa data curah hujan pada pembahasan sub bab 3.1 terdahulu, tidak ada nilai intensitas hujan yang lamanya sama dengan nilai Tc dari hasil perhitungan pada sub bab $3.2(43,2275$ menit atau 0,72 jam).

Dari beberapa nilai intensitas hujan yang bahwa kejadian hujan seragam/konstan selama 1 jam, maka nilai intensitas hujan menurut Fadli Syamsudin dapat sebagai berikut untuk Tc selama 43,2275 menit atau 0,72 jam adalah :

$\mathrm{i}_{0,72}=[80+\{0,5 \times(100-80)\} \times(43,2275 / 60)$

$=64,84 \mathrm{~mm} / \mathrm{jam}$

Sedikit catatan, sebetulnya metode yang paling tepat untuk menentukan besarnya intensitas hujan dengan waktu yang kurang dari 1 jam (hitungan menit tertentu) adalah dengan menggunakan kurva Intensity Duration Curve (IDF). Namun karena sulitnya memperoleh data curah hujan yang untuk periode jam-jaman, maka kurva IDF ini masih menjadi sesuatu yang langka dan sulit dibuat di Indonesia.

Dengan menggunakan data yang ada, besarnya intensitas hujan $\left(\mathrm{i}_{0,72}\right)$ sebesar $64,84 \mathrm{~mm} /$ jam ; koefisien aliran $(C)$ berdasarkan perhitungan pada Tabel 3 sebesar 0,5805 ; dan luas catchment area (A) menurut Tabel 1 seluas 112,5 ha, maka besarnya debit puncak (Qmaks) berdasarkan Persamaan 3 adalah sebagai berikut :

$\mathrm{Qp}=0,0028 \times 0,5953 \times 64,84 \mathrm{~mm} / \mathrm{jam} \times 112,5$ ha $=12,16 \mathrm{~m}^{3} / \mathrm{dt}$.

\subsection{Penambahan Volume Air dan Kenaikan Muka Air}

Perhitungan terhadap jumlah air yang masuk selama hujan dilakukan dengan cara menghitung tebal hujan dikalikan luas catchment area. Tebal hujan dalam sehari menggunakan data curah hujan dari Stasiun Meteorologi Ciputat yaitu sebesar $113,2 \mathrm{~mm}$ dan luas catchment area 112,5 ha. Dalam perhitungan ini pengaruh evapotranspirasi diabaikan dan seluruh air hujan 
yang jatuh dalam catchment area Situ Gintung diasumsikan masuk ke dalam tubuh air, baik yang jatuh langsung di atas tubuh air maupun yang jatuh di bagian daratan. Dengan demikian jumlah volume air yang masuk adalah :

Volume $=$ Tebal hujan $\mathrm{x}$ Luas DAS

$$
\begin{aligned}
& =(113,2 \mathrm{~mm} / 1000) \times(112,5 \times 10.000) \\
& =127.350 \mathrm{~m}^{3}
\end{aligned}
$$

Berdasarkan tinjauan hidrologi dapat dijelaskan bahwa telah terjadi peningkatan debit puncak mencapai 18,286 m3/dt dengan tambahan volume air sebesar $127.350 \mathrm{~m}^{3}$, yang dipicu oleh hujan setebal 113,2 $\mathrm{mm}$ dalam sehari.

Dari hasil perhitungan volume air yang masuk ke Situ Gintung di atas, maka dengan penambahan volume air sebesar $127.350 \mathrm{~m}^{3}$ dan asumsi luasan situ seluas 16,2 ha, maka terjadi kenaikan muka air setinggi $127.350 \mathrm{~m}^{3} / 16,2$ ha $=$ $78,61 \mathrm{~cm}$.

\section{Pembahasan}

Jika mengacu pada keterangan Fadli Syamsudin(Kompas, 1April2009)yangmenyatakan bahwa di sekitar lokasi kejadian terjadi hujan dengan intensitas tinggi mulai siang hari (tanggal 26 Maret 2009) pukul 13.00 sampai dengan malam hari pukul 19.30 (ada jeda waktu 1,5 jam dari pukul 14.30 sampai dengan pukul 19.30) dan perhitungan waktu konsentrasi untuk catchment area Situ Gintung memerlukan waktu sekitar 43,22 menit atau 0,72 jam, maka curah hujan bukan merupakan faktor utama penyebab jebolnya tanggul. Mengapa demikian, karena peristiwa jebolnya tanggul terjadi pada sekitar pukul 05.30 tanggal 27 Maret 2009, atau ada waktu sekitar 10 jam dan ini sudah jauh melebihi waktu konsentrasi yang terjadi. Hal ini juga diperkuat dengan keterangan Sutopo Purwo Nugroho (Kompas, 1 April 2009) yang menyatakan bahwa di daerah tersebut pernah terjadi hujan dengan intensitas yang jauh lebih tinggi daripada kejadian hujan tanggal 26 Maret 2009, yaitu pada tahun 1996 (180 mm/hari) dan tahun 2007 (275 $300 \mathrm{~mm} /$ hari), dimana pada kedua kejadian hujan tersebut kondisi Jakarta banjir besar, sementara kondisi tanggul Situ Gintung sendiri tetap aman.

Pertanyaannya adalah, apa penyebab utama jebolnya tanggul Situ Gintung tersebut? Penulis berpendapat bahwa kondisi tanggul yang memang sudah rusak/mengalami kebocoran sebelumnya merupakan penyebab utama musibah tersebut. Berdasarkan informasi beberapa surat kabar dan media televisi, masyarakat sekitar sudah mengetahui terjadinya kebocoran pada tanggul situ beberapa minggu sebelum kejadian. Keadaan ini sudah dilaporkan kepada pemerintah melalui aparat desa setempat, sayangnya hal ini tidak segera mendapat respon serius. Suatu bangunan reservoir baik waduk ataupun situ dibangun dengan desain untuk umur ekonomis (life time) tertentu, yang tergantung pada tingkat resiko yang diambil berdasarkan periode ulang yang dipilih. Jika melihat pada sejarahnya, situ didesain untuk sarana irigasi, sehingga kemungkinan Pemerintah Belanda dahulu membangun situ tidak untuk umur ratusan tahun. Berubahnya fungsi lahan, dari lahan pertanian menjadi areal permukiman padat saat ini merupakan kesalahan besar. Hal ini mungkin tidak dipertimbangkan oleh Pemerintah Belanda pada saat mendesain pembangunan situ ini. Jadi, karena umur tanggul yang sudah dalam 'kondisi lelah' inilah yang menyebabkan tanggul tersebut jebol dengan adanya tambahan curah hujan sebesar 113,2 mm/ hari. Kondisi serupa diyakini oleh penulis terjadi untuk hampir seluruh situ di sekitar Jabodetabek buatan Pemerintah Belanda dulu yang saat ini masih ada. Oleh karena itu, pemerintah perlu memperhatikan hal tersebut belajar dari musibah yang telah menimpa Situ Gintung.

Jika melihat besarnya debit puncak berdasarkan hasil perhitungan yang sebesar $12,16 \mathrm{~m}^{3} /$ detik, nilai tersebut sebenarnya belum terlalu melebihi kapasitas spillway. Menurut keterangan Dirjen Sumber Daya Air Departemen Pekerjaan Umum, Iwan Nusyirwan Diar, spillway mampu mengalirkan $12 \mathrm{~m}^{3} /$ detik (Antara News, 1 April 2009). Sayangnya dalam penelitian ini penulis tidak mendapatkan data berapa tinggi muka air (TMA) Situ Gintung pada saat sebelum kejadian dan berapa ketinggian elevasi bangunan spillway yang ada, sehingga dengan diperolehnya perhitungan tambahan volume air dan kenaikan TMA pada sub bab 3.5 tidak dapat diketahui apakah saat kejadian volume air situ melimpas atau tidak. Namun, sekalipun diasumsikan pada saat itu terjadi limpasan, seharusnya hal tersebut tidak menjadi masalah karena berdasarkan hasil perhitungan debit puncak masih berada di bawah kapasitas debit spillway seperti dijelaskan di atas. Yang pasti, akibat adanya penambahan volume air sebanyak $127.350 \mathrm{~m}^{3}$ dan kenaikan TMA setinggi $78,61 \mathrm{~cm}$ telah menyebabkan tekanan hidrostatik air terhadap tanggul meningkat, apalagi di bagian outlet.

Berdasarkan hasil pengamatan lapangan penulis ke lokasi kejadian, di bagian outlet Situ Gintung pada saat sebelum kejadian hanya tinggal satu saluran pembuangan yang masih ada, yaitu di titik dimana jebolnya tanggul tersebut. Dari keterangan Kepala Balai Besar Wilayah Sungai Ciliwung Cisadane, Pitoyo Subandrio (Kompas, 28 Maret 2009), saluran pembuangan yang awalnya dibangun oleh Pemerintah Belanda dulu selebar 5 - 7 meter, saat ini saluran tersebut hanya tinggal selebar 1 meter. Mengapit saluran pembuangan 
utama yang menjadi titik dimana tanggul jebol, pada sisi sudut timur maupun barat bagian outlet juga terdapat pintu air sebagai saluran pembuangan sekunder. Lebar saluran saat ini hanya tinggal 30 $\mathrm{cm}$. Penulis juga meyakini bahwa sama dengan kondisi saluran primer, kedua saluran sekunder tersebut pada awalnya jauh lebih lebar daripada kondisi sekarang.

Kombinasi dari berbagai permasalahan di atas; umur bangunan tanggul Situ Gintung yang sudah dalam 'kondisi lelah' dan kondisi sekarang yang sudah tidak sesuai dengan kondisi pada saat dibangun oleh Pemerintah Belanda dinilai sebagai faktor utama penyebab tragedi pada tanggal 27 Maret 2009 yang lalu. Memang curah hujan saat itu juga sebagai faktor penyebab, tapi bukan sebagai faktor utama. Jika tidak terkondisi sebagaimana yang sudah dipaparkan di atas, maka hujan yang terjadi sesaat sebelum tragedi tersebut kemungkinan besar tidak akan membawa malapetaka yang sangat merugikan tersebut.

Gambar 2, 3 dan 5 memperlihatkan kondisi topografi berdasarkan DEM dan profil 3 dimensi dari catchment area Situ Gintung. Titik lokasi jebolnya tanggul merupakan titik dimana lokasi tanggul memiliki perbedaan elevasi tertinggi (sekitar 20 meter) dengan daerah di luar catchment area. Selain itu lokasi tersebut merupakan areal permukiman padat. Dapat dibayangkan bagaimana dahsyatnya air yang mengalir saat tanggul tersebut jebol dan menimpa daerah permukiman yang ada di bawahnya.

Dari peristiwa jebolnya tanggul Situ Gintung ini, penulis menghimbau agar pemerintah pusat melalui instansi yang terkait segera melakukan evaluasi dan inspeksi terhadap beberapa situ yang ada di sekitar wilayah Jabodetabek. Diyakini hampir semua situ yang masih ada sekarang memiliki kondisi yang sama dengan Situ Gintung karena dibangun hampir pada masa yang bersamaan dengan Situ Gintung oleh Pemerintah Belanda dahulu. Peristiwa ini juga sekaligus memberikan pelajaran bahwa Tata Ruang Wilayah yang saat ini sudah banyak dilanggar dan tidak sesuai lagi dengan peruntukkannya (sebagai contoh, beberapa situ diurug untuk dijadikan areal permukiman atau mall; atau dari kasus Situ Gintung sendiri dimana areal permukiman padat yang menjadi areal musibah sebenarnya dahulu merupakan areal pertanian) dapat memberikan kerugian besar, baik moril maupun materil. Sebagai penutup penulis berharap agar pelajaran dari tragedi Situ Gintung ini mendapat perhatian serius dari Pemerintah selaku penentu kebijakan dalam kaitannya dengan tindakan konservasi yang sangat diperlukan untuk menyelamatkan kota Jakarta khususnya, yang pada kondisi sekarang ini sudah memiliki permasalahan degradasi lingkungan yang sangat kompleks.

\section{Kesimpulan}

Dari hasil analisis yang telah dilakukan, maka dapat ditarik beberapa kesimpulan sebagai berikut :

1. Faktor curah hujan juga turut mempengaruhi penyebab jebolnya tanggul Situ Gintung, namun bukan sebagai faktor utama. Ada beberapa alasan yang mendasari kesimpulan ini, yaitu :

a. Peristiwa jebolnya tanggul terjadi pada selang waktu sekitar 10 jam setelah hujan dengan intensitas tinggi berlangsung, sementara waktu konsentrasi untuk catchment area Situ Gintung hanya memerlukan waktu relatif singkat, yaitu sekitar 43 menit.

b. Hujan dengan intensitas yang lebih besar dibandingkan curah hujan pada tanggal 26 Maret 2009 (113,2 mm/hari) pernah terjadi di daerah tersebut, yaitu pada tahun 1996 (180 mm/hari) dan tahun 2007 (275 - $300 \mathrm{~mm} /$ hari), dimana pada kedua kejadian hujan tersebut kondisi Jakarta banjir besar, sementara kondisi tanggul Situ Gintung sendiri tetap aman.

c. Berdasarkan perhitungan periode ulang kejadian hujan di daerah Ciputat, curah hujan setebal 113,2 mm/hari dapat terjadi untuk periode ulang 5 tahun. Hal ini berarti bahwa curah hujan dengan kondisi seperti pada tanggal 26 Maret 2009 tersebut dapat terjadi sebanyak 15 kali semenjak pertama kalinya dibangun (tahun 1932-1933) hingga tahun 2009, dan ini dapat dianggap tidak beresiko menimbulkan bahaya dengan peluang frekuensi terjadinya yang cukup sering tersebut.

2. Faktor utama penyebab jebolnya tanggul Situ Gintung adalah karena usia bangunan tanggul yang sudah tua yang semakin diperparah dengan kondisi saluran pembuangan yang sudah tidak berfungsi sebagaimana pada saat awal dibangun oleh Pemerintah Belanda dulu.

3. Lebar saluran pembuangan yang jauh berkurang dan semakin menyempit dibandingkan dengan kondisi awal saat dibangun oleh Pemerintah Belanda dulu, menyebabkan beban tanggul semakin berat karena tekanan hidrostatik air di dalam Situ semakin besar. 


\section{DAFTAR PUSTAKA}

Antara News. 2009. Pemerintah Yakin Secara Struktur Situ Gintung Kuat. Situs www.antara co.id, 1 April 2009.

Brigitta Isworo Laksmi. 2009. Tanggul, Pemicu dan Audit Teknologi. Artikel dalam Harian Kompas, 1 April 2009, Jakarta.

Dedi Kusnadi Kalsim. 2009. Pendugaan Puncak Limpasan. Laboratorium Teknik Tanah dan Air, FATETA Institut Pertanian Bogor. Bogor.

Departemen Pekerjaan Umum bekerjasama dengan Lavalin Int. Inc., Nippon Koei Co.Ltd. 1987. Laporan Kegiatan Project Cisadane River Basin Development Fisibility Study tahun 1987, Departemen Pekerjaan Umum Republik Indonesia. Jakarta.
Fadli Syamsudin. 2009. Faktor Cuaca Pada Bencana Situ Gintung. Artikel dalamr Harian Kompas, 1 April 2009, Jakarta.

Fahmi Firdaus. 2009. BMG: Situ Gintung Jebol Dipicu Cuaca Ekstrim. Situs www.okezone com , 31 Maret 2009

Gatot Irianto. 2009. Bobolnya Situ Gintung. Artikel dalam Harian Kompas, 2 April 2009, Jakarta.

Mulyawan Karim. Kompas, 2009. Setelah 76 Tahun, Tanggul Buatan Belanda Itu Pun Jebol. Artikel dalam Harian Kompas, 28 Maret 2009, Jakarta. 
